\title{
Diagnostic efficacy of cone beam computed tomography in paediatric dentistry: a systematic review
}

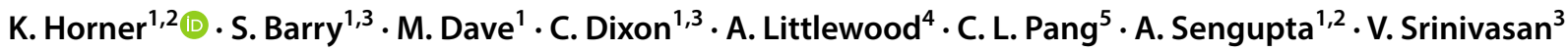

Received: 12 September 2019 / Accepted: 10 December 2019 / Published online: 19 December 2019

(c) The Author(s) 2019, corrected publication 2020

\begin{abstract}
Purpose To determine in which clinical situations it is indicated or contra-indicated to prescribe cone beam computed tomography (CBCT) for paediatric patients.

Methods Systematic review of in vivo paediatric research studies of diagnostic efficacy using CBCT, with supplementary searches for guideline documents on CBCT and for systematic reviews permitting inclusion of ex vivo and adult studies.

Results After screening, 190 publications were included, mostly case studies. No systematic reviews were found of in vivo paediatric research. Fourteen studies of diagnostic efficacy were identified. The supplementary searches found 18 guideline documents relevant to the review and 26 systematic reviews. The diagnostic efficacy evidence on CBCT was diverse and often of limited quality. There was ex vivo evidence for diagnostic accuracy being greater using CBCT than radiographs for root fractures. The multiplanar capabilities of CBCT are advantageous when localising dental structures for surgical planning. Patient movement during scanning is more common in children which could reduce diagnostic efficacy.

Conclusions No strong recommendations on CBCT are possible, except that it should not be used as a primary diagnostic tool for caries. Guidelines on use of CBCT in the paediatric age group should be developed cautiously, taking into account the greater radiation risk and the higher economic costs compared with radiography. CBCT should only be used when adequate conventional radiographic examination has not answered the question for which imaging was required. Clinical research in paediatric patients is required at the higher levels of diagnostic efficacy of CBCT.
\end{abstract}

Keywords Cone beam computed tomography $\cdot$ Radiography, dental $\cdot$ Paediatric dentistry $\cdot$ Diagnosis

\section{Introduction}

Electronic supplementary material The online version of this article (https://doi.org/10.1007/s40368-019-00504-x) contains supplementary material, which is available to authorized users.

\section{K. Horner}

keith.horner@manchester.ac.uk

1 Division of Dentistry, School of Medical Sciences, Faculty of Biology, Medicine and Health, University of Manchester, Manchester Academic Health Science Centre, Coupland Building 3, Manchester M13 9PL, UK

2 Dental Radiology, University Dental Hospital of Manchester, Manchester University NHS Foundation Trust, Manchester Academic Health Science Centre, Higher Cambridge Street, Manchester M15 6FH, UK

3 Paediatric Dentistry, University Dental Hospital of Manchester, Manchester University NHS Foundation
Cone beam computed tomography (CBCT) is used for a wide variety of dental diagnostic uses, including in children and young people (Aps 2013). CBCT typically has a radiation dose one or more orders of magnitude greater

Trust, Manchester Academic Health Science Centre, Higher Cambridge Street, Manchester M15 6FH, UK

4 Information Specialist, Cochrane Oral Health, Division of Dentistry, School of Medical Sciences, Faculty of Biology, Medicine and Health, University of Manchester, Manchester Academic Health Science Centre, Coupland Building 3, Manchester M13 9PL, UK

5 Division of Imaging, Manchester Royal Infirmary, Manchester University NHS Foundation Trust, Manchester Academic Health Science Centre, Oxford Road, Manchester M13 9WL, UK 
than that for conventional radiography (Theodorakou et al. 2012; European Commission 2012; Ludlow et al. 2015). This is important in paediatric use because of the higher levels of risk associated with X-ray exposure in young age groups. This has stimulated efforts on justification and dose optimisation of CBCT in the paediatric context (Law et al. 2014; White et al. 2014; Oenning et al. 2018). In addition, the financial costs of using CBCT instead of, or in addition to, conventional imaging is likely to raise the overall costs of healthcare, unless its use leads to cost-savings elsewhere along the patient care pathway.

Radiation dose and risk are not primary determinants of whether or not to use a diagnostic X-ray technique. A fundamental principle of radiation protection, justification, requires that the potential benefits of its use outweigh the risk. Fryback and Thornbury (1991) devised a hierarchical model of diagnostic efficacy which conceptualises the benefits (Table 1). Evidence of efficacy at the lower levels does not guarantee that it exists at higher levels. Criteria for using an imaging modality should be based on evidence rather than opinion, ideally on a body of evidence at the higher levels of diagnostic efficacy with a low risk of bias.

There are a substantial number of guidelines published related to the clinical use of CBCT including referral guidelines, also known as "appropriateness criteria" and "selection criteria". These were reviewed by Horner et al. (2015), but very little was found specifically on paediatric use of CBCT. The underlying reason for this systematic review was to address this deficiency. The aim was to determine in which clinical situations and paediatric age groups is it indicated or contra-indicated to prescribe CBCT. To achieve this aim, an overall review question was developed: "what are the indications and contra-indications for the use of cone beam computed tomography (CBCT) in the dental care of children and young people as part of diagnosis and management?"

\section{Materials and methods}

\section{Protocol and registration}

The protocol for this systematic review was registered on the International Prospective Register of Systematic Reviews (PROSPERO) and can be accessed at https://www.crd.york. ac.uk/PROSPERO/display_record.asp?ID=CRD4201810 9768.

\section{Eligibility criteria}

\section{Study designs}

In vivo paediatric studies of diagnostic efficacy as defined by Fryback and Thornbury (1991) (Table 1).

Included:

- Systematic reviews of in vivo diagnostic efficacy studies.

- Primary studies of in vivo diagnostic efficacy (if not included in a systematic review).

- Narrative reviews, case series, case reports, surveys of clinical use of CBCT and other research study designs (observational studies; observer reliability studies) and guideline documents as secondary sources of information.

Excluded:

- Studies of technical efficacy (level 1, Table 1)

- Studies of any design for which the objectives were to evaluate treatments, in which the use of CBCT was simply as a diagnostic tool.

- Ex vivo/in vitro studies

- Animal studies.

Table 1 The hierarchical Model of diagnostic efficacy. Adapted from Fryback and Thornbury (1991)

\begin{tabular}{ll}
\hline Level & Example measures of analyses \\
\hline Level 6: Societal efficacy & $\begin{array}{c}\text { Economic evaluation/cost analysis/cost-effectiveness evaluation from a societal standpoint; cost per } \\
\text { outcome change } \\
\text { e.g. proportion of patients improved pre-test to post-test; morbidity or procedures avoided after having } \\
\text { test results }\end{array}$ \\
$\begin{array}{ll}\text { e.g. proportion of cases in which prospectively stated treatment plan changed pre-test to post-test } \\
\text { Level 4: Therapeutic efficacy }\end{array}$ & $\begin{array}{l}\text { e.g. difference in clinicians' pre- and post-test diagnoses; change in percentage of cases in a series in } \\
\text { which the image was judged to be "helpful" in making diagnosis }\end{array}$ \\
Level 2: Diagnostic accuracy efficacy & $\begin{array}{l}\text { Sensitivity; specificity; predictive vales; diagnostic odds ratios; ROC curve analysis } \\
\text { Level 1: Technical efficacy }\end{array}$ \\
& $\begin{array}{l}\text { Spatial resolution; grey-scale; contrast-noise ratio; sharpness; Modulation Transfer Function (MTF); } \\
\text { linear accuracy }\end{array}$
\end{tabular}


- Research on orthodontic applications of CBCT, although flexibility was permitted if these had relevance to paediatric dentistry.

- Radiation dosimetry studies.

\section{Participants}

Children and young people (under 18 years) under care for any of six clinical contexts (caries, acute dental infections, dental trauma, dental anomalies, developmental disorders and pathological conditions). A seventh category of clinical context was added to encompass "other uses" of CBCT. We included studies that included both adults and children/ young people at the same time if data for the latter group could be extracted. We excluded studies solely restricted to adults ( 18 years or over) unless the clinical context was judged to be clearly also applicable to children and young people.

\section{Intervention}

CBCT used for dental diagnostic purposes. We excluded studies using multislice ("medical") computed tomography (CT) and CBCT equipment not designed for dental use.

\section{Comparators}

For diagnostic accuracy (level 2) studies (Table 1), a reference standard comparator was essential (surgical evidence; histopathological; microCT; other method judged to have sufficient validity). For studies at levels 2-6 (inclusive) of diagnostic efficacy, comparison with conventional dental radiography (intraoral, panoramic and cephalometric radiography), another imaging modality or other diagnostic test was expected. For research at the societal efficacy level (level 6), studies without a comparator were considered for inclusion on an individual basis.

\section{Outcomes}

For the use of CBCT in each of the six clinical contexts being studied, in comparison with the alternative imaging method(s) or, in the case of no comparator imaging, clinical assessment alone:

- Change in one or more measures of diagnostic accuracy.

- Change in diagnostic thinking, including clinicians' confidence in their diagnosis or the perceived helpfulness of the imaging in reaching a diagnosis.

- Change in management decision(s), including clinicians' confidence in their decision(s) or the perceived helpfulness of the imaging in making the decision(s).

- Change in patient outcome after the treatment of the condition.

- Change in costs, cost-utility, cost-effectiveness or other economic measure(s) of efficacy.

\section{Setting}

Studies in either a primary or a secondary dental healthcare setting.

\section{Language}

English language studies or at least an English abstract. Studies in other languages were considered for inclusion pragmatically if there was a means of translation within the review team.

\section{Information sources and searches}

Literature search strategies were developed using medical subject headings (MeSH) and text words related to CBCT, children and young people, and dental diseases. Parts of this search strategy were adapted from Leclercq et al. (2013). Search details are presented in Tables 2 and 3.

Table 2 The databases searched for the systematic review

\begin{tabular}{|c|c|c|c|}
\hline $\begin{array}{l}\text { MEDLINE Ovid (inc ePub ahead of print, pre- } \\
\text { indexed etc.) }\end{array}$ & 1409 & PROSPERO* & 71 \\
\hline Embase Ovid & 856 & $\begin{array}{l}\text { US National Institutes of Health Trials Registry (ClinicalTrials. } \\
\text { gov)* }\end{array}$ & 34 \\
\hline Proquest Dissertations and Theses & 120 & WHO International Clinical Trials Registry Platform* & 4 \\
\hline Web of Science Conference Proceedings & 12 & & \\
\hline
\end{tabular}

Date of search 08.10.2018. Dates of search coverage 1998-October 2018 except for those marked $(*)$, for which searches of the whole database were made

Total number of papers retrieved: $2506-731$ duplicates $=1775$ used for this review 
Table 3 Medline Ovid search strategy

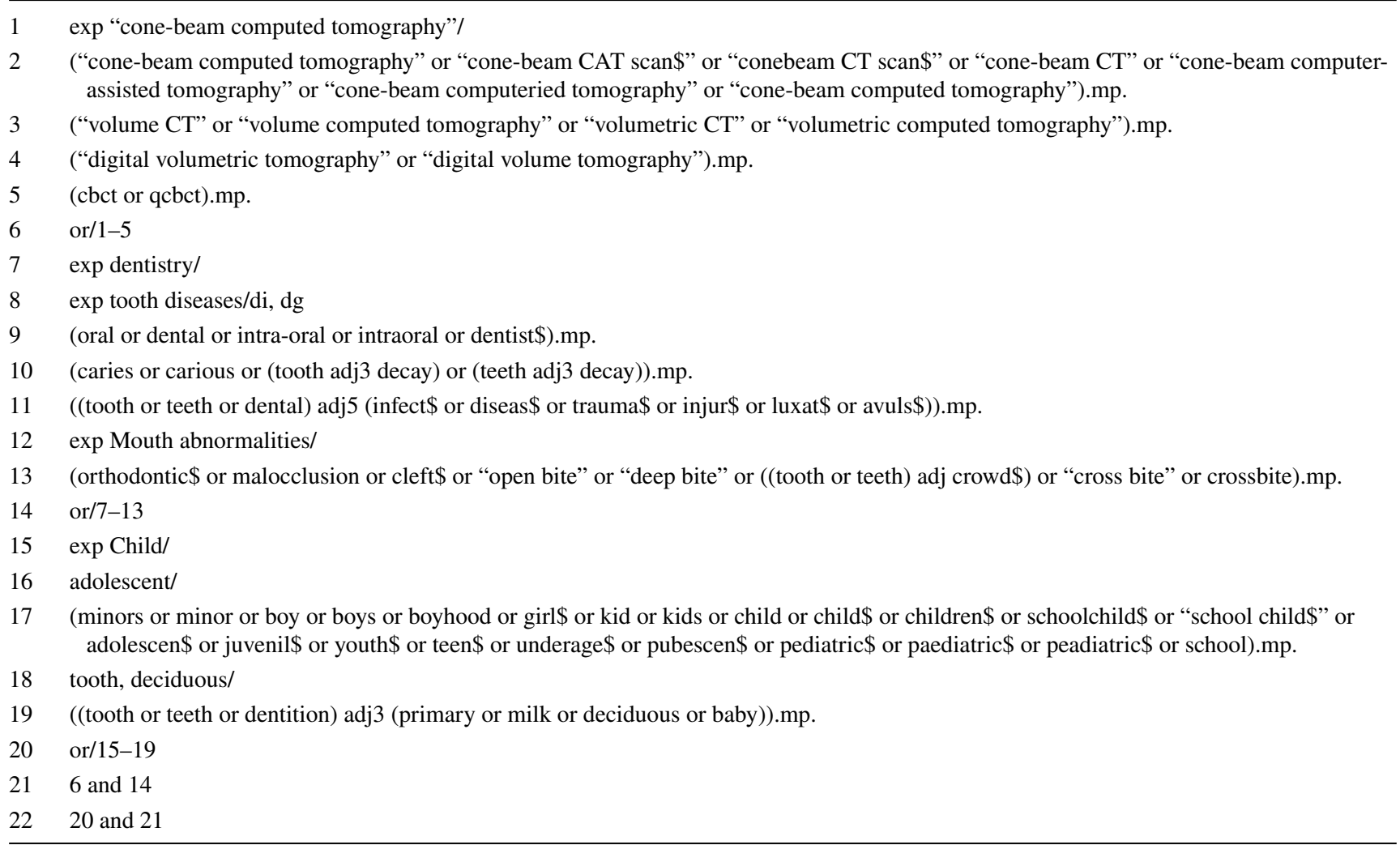

Lines 15-20 of the search strategy were adapted from Leclercq et al. (2013). The Embase Ovid search strategy is not presented as it was essentially the same, with only minor differences in terms, e.g. for Embase Ovid, line 12 was "Mouth malformation/di" and line 18 was "Deciduous tooth/"

\section{Study selection}

EndNote was used to compile the searches and de-duplicate references. Retrieved titles and abstracts were screened by pairs of review authors from the team independently to identify publications that potentially met the inclusion criteria. The screened lists were reviewed by a third team member who combined them into a single list. The full text of these potentially eligible studies was retrieved and independently assessed by two review team members. Disagreement over eligibility was resolved through discussion with a third reviewer. Studies were classified according to the six clinical contexts (plus "other uses") and ten study design types (systematic review, the five levels of diagnostic efficacy, narrative reviews, case series/reports/surveys, other research study designs, clinical guidelines).

\section{Data collection process}

Standardised forms were used to extract data from the included studies for assessment of study quality and evidence synthesis. For primary studies of diagnostic efficacy, two review authors extracted data independently and discrepancies were identified and resolved through discussion (with a third author where necessary). Extracted information included: study setting (primary or secondary care; study population, demographics and presenting characteristics; CBCT equipment used and operating parameters; comparator imaging (if used); study methodology; observer/rater profile; recruitment and study completion rates; outcomes; information for assessment of the risk of bias. For other study types, a specific form was used to record the relevant data. Case reports with fewer than five individual cases were not formally reviewed, but were collated to provide an indication of the uses to which CBCT has been applied.

\section{Risk of bias in individual studies}

The two review authors independently assessed the risk of bias in systematic reviews and primary studies of diagnostic efficacy. The tools planned for critical appraisal are shown in Table 4. Disagreement was resolved by discussion and, if required, by involvement of a third reviewer. 
Table 4 Critical appraisal tools planned for review of systematic reviews of diagnostic efficacy and primary studies of diagnostic efficacy arising from the main review search

\begin{tabular}{ll}
\hline Study type & Tool \\
\hline Systematic reviews & AMSTAR-2 (Shea et al. 2017) \\
Diagnostic accuracy efficacy & QUADAS 2 (Whiting et al. 2011) \\
Diagnostic thinking efficacy & Modified QUADAS (Meads and Davenport 2009) \\
Therapeutic efficacy & Modified QUADAS (Meads and Davenport 2009) \\
Patient outcome efficacy & Cochrane Handbook for Systematic Reviews of Interventions, Version 5.1.0 (Higgins and Green 2011) \\
Societal efficacy & For studies including a patient outcome assessment, Consensus Health Economic Criteria (CHEC) list \\
& (Evers et al. 2005) \\
& For cost analysis studies without a patient outcome assessment, the proforma used by Christell et al. \\
& (2014) based on Drummond et al. (2005) \\
\hline
\end{tabular}

\section{Data synthesis}

We undertook a systematic narrative synthesis to explore the relationship and findings both within and between the included studies. The purpose was to present clearly, for each clinical condition, information which allowed identification of indications and contra-indications for CBCT.

\section{Supplementary information}

Following initial scoping searches, it became apparent that the eligibility criteria for the main search would be highly restrictive. Therefore, two supplementary searches for information relevant to the review were undertaken. The first identified existing clinical guidelines on the use of CBCT. The second was a broad search for systematic reviews on diagnostic efficacy using CBCT which included ex vivo/in vitro studies and in vivo studies of (or including) adult patients. These are described in Online Resources 1 and 2, respectively.

\section{Results}

\section{Study selection}

Figure 1 shows the flow of the articles identified through our main search. One hundred and ninety publications were included, listed in Online Resource 3. Table 5 shows the allocation of the included studies according to the clinical context and the study type. Some studies fell into multiple clinical contexts, so the summed numbers in Table 5 exceed the 190 shown in Fig. 1. Publications were overwhelmingly in the case series, case report and survey category.

No systematic review from the main search strategy satisfied the inclusion criteria. There were 14 primary research studies of diagnostic efficacy; for these, flexibility in the inclusion criteria was permitted. Four of these appeared in both Level 3 and Level 4 categories of diagnostic efficacy
(Haney et al. 2010; Katheria et al. 2010; Botticelli et al. 2011; Wriedt et al. 2017). No patient outcome efficacy study was identified. The evidence from the 14 diagnostic efficacy studies is summarised in Table 6.

Case series presenting fewer than five cases are listed in Online Resource 4, with their specific clinical context. The overwhelming proportion fell into the dental anomalies category; none was in the caries category and only one in the acute dental infections category. Twenty-four case series presenting five or more patient subjects were considered in greater detail. Three publications were allocated to the guidelines category (Noffke et al. 2011; American Academy of Pediatric Dentistry 2012; Law et al. 2014), although the last of these was of a very general nature and not solely directed at $\mathrm{CBCT}$.

\section{Supplementary information}

The results of the two supplementary searches for information relevant to the review are described in Online Resources 1 and 2 , respectively.

\section{Risk of bias within systematic reviews and diagnostic efficacy studies}

Assessments of risk of bias of the 14 diagnostic efficacy studies are given in Online Resource 5. For the diagnostic accuracy category, the four studies (Murphy et al. 2012; Ziegler and Klimowicz 2013; Sansare et al. 2014; Mak 2015) fell into different clinical contexts and none was rated uniformly as free of risk of bias or without concerns about applicability. The results of quality assessment of diagnostic thinking efficacy and therapeutic efficacy studies are presented using a visual analogue scale, following a previous review method (Horner and Shelley 2016). No study was assessed at the highest level of quality, but two (Katheria et al. 2010; Jawad et al. 2016) were assessed below the mid-point of the scale for quality. The two societal efficacy publications (Christell et al. 2012a, b) 
Fig. 1 PRISMA flow chart (Moher et al. 2009) showing the flow of publications arising from the main search

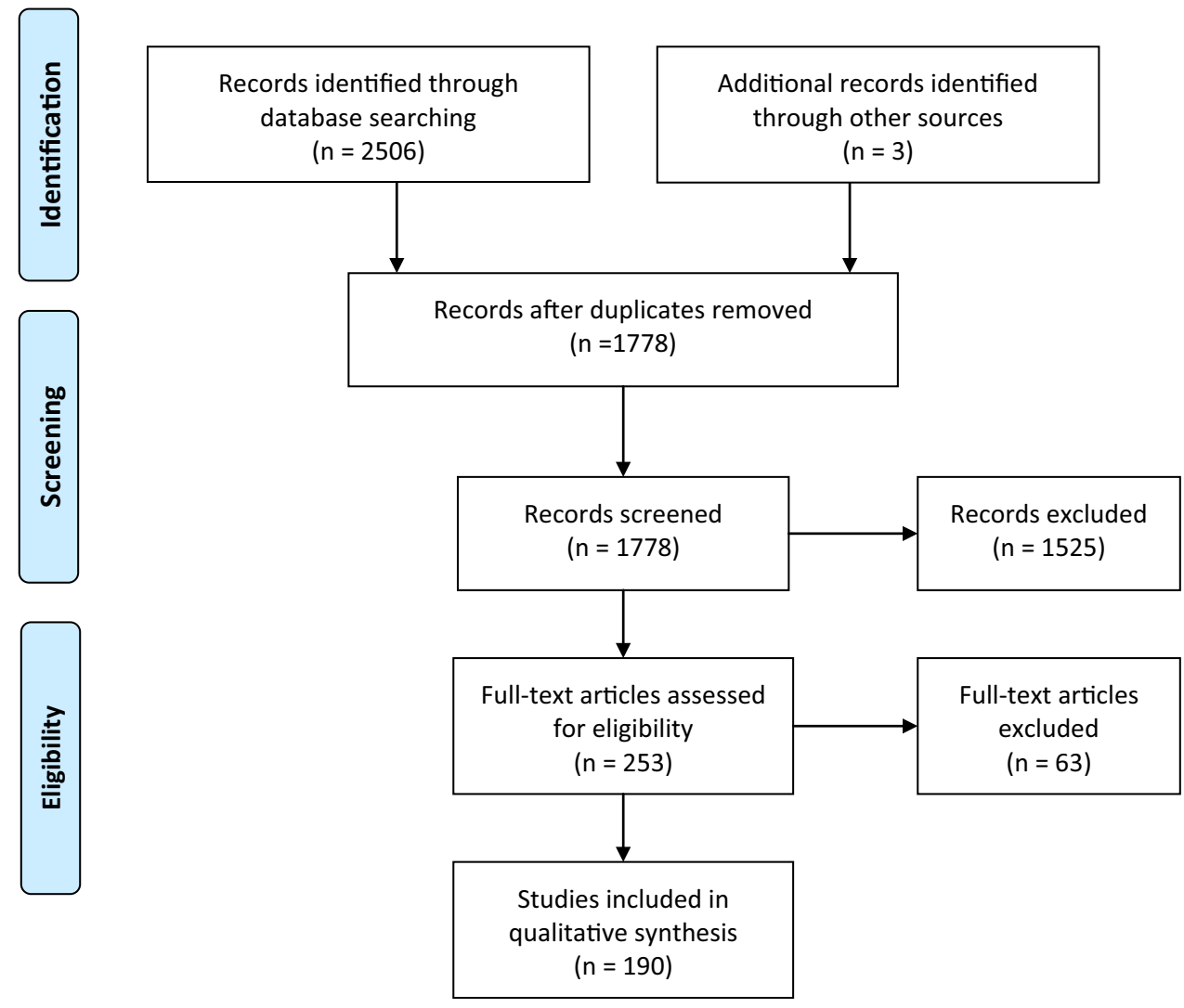

Table 5 Allocation of the included studies in the review, according to the clinical context and the study type

\begin{tabular}{|c|c|c|c|c|c|c|c|}
\hline Study type & Caries & $\begin{array}{l}\text { Acute dental } \\
\text { infections }\end{array}$ & Dental trauma & $\begin{array}{l}\text { Dental } \\
\text { anomalies }\end{array}$ & $\begin{array}{l}\text { Developmen- } \\
\text { tal disorders }\end{array}$ & $\begin{array}{l}\text { Pathological } \\
\text { conditions }\end{array}$ & Other uses \\
\hline Systematic reviews of diagnostic efficacy & 0 & 0 & 0 & 0 & 0 & 0 & 0 \\
\hline Diagnostic accuracy efficacy & 1 & 0 & 0 & 1 & 0 & 1 & 1 \\
\hline Diagnostic thinking efficacy & 0 & 0 & 1 & 4 & 1 & 5 & 0 \\
\hline Therapeutic efficacy & 0 & 0 & 0 & 3 & 1 & 1 & 0 \\
\hline Patient outcome efficacy & 0 & 0 & 0 & 0 & 0 & 0 & 0 \\
\hline Societal efficacy & 0 & 0 & 0 & 2 & 0 & 0 & 0 \\
\hline Narrative reviews & 4 & 3 & 4 & 4 & 3 & 4 & 4 \\
\hline Case series/case reports/surveys & 3 & 4 & 11 & 65 & 15 & 29 & 26 \\
\hline Other research study designs & 0 & 0 & 0 & 0 & 10 & 6 & 19 \\
\hline Clinical guidelines & 1 & 1 & 1 & 1 & 1 & 1 & 3 \\
\hline
\end{tabular}

were both cost analyses, a design that lacks any measurement of patient outcomes. Because of this, the Consensus Health Economic Criteria (CHEC) list (Evers et al. 2005) could not be used and the proforma used by Christell et al. (2014), based on Drummond et al. (2005), was substituted. This method does not translate to a numerical or categorical descriptor of risk of bias, but the results suggested that Christell et al. (2012b) had a low risk of bias, while Christell et al. (2012a) was judged slightly less favourably because no comparator imaging was included.

\section{Results according to clinical context}

A comprehensive description of the findings of the review and the supplementary searches according to the clinical contexts is provided in Online Resource 6 and only a summary is provided here. Overall, there was very little evidence available specific to the paediatric age group; so, the evidence from the supplementary search for systematic reviews became important. 


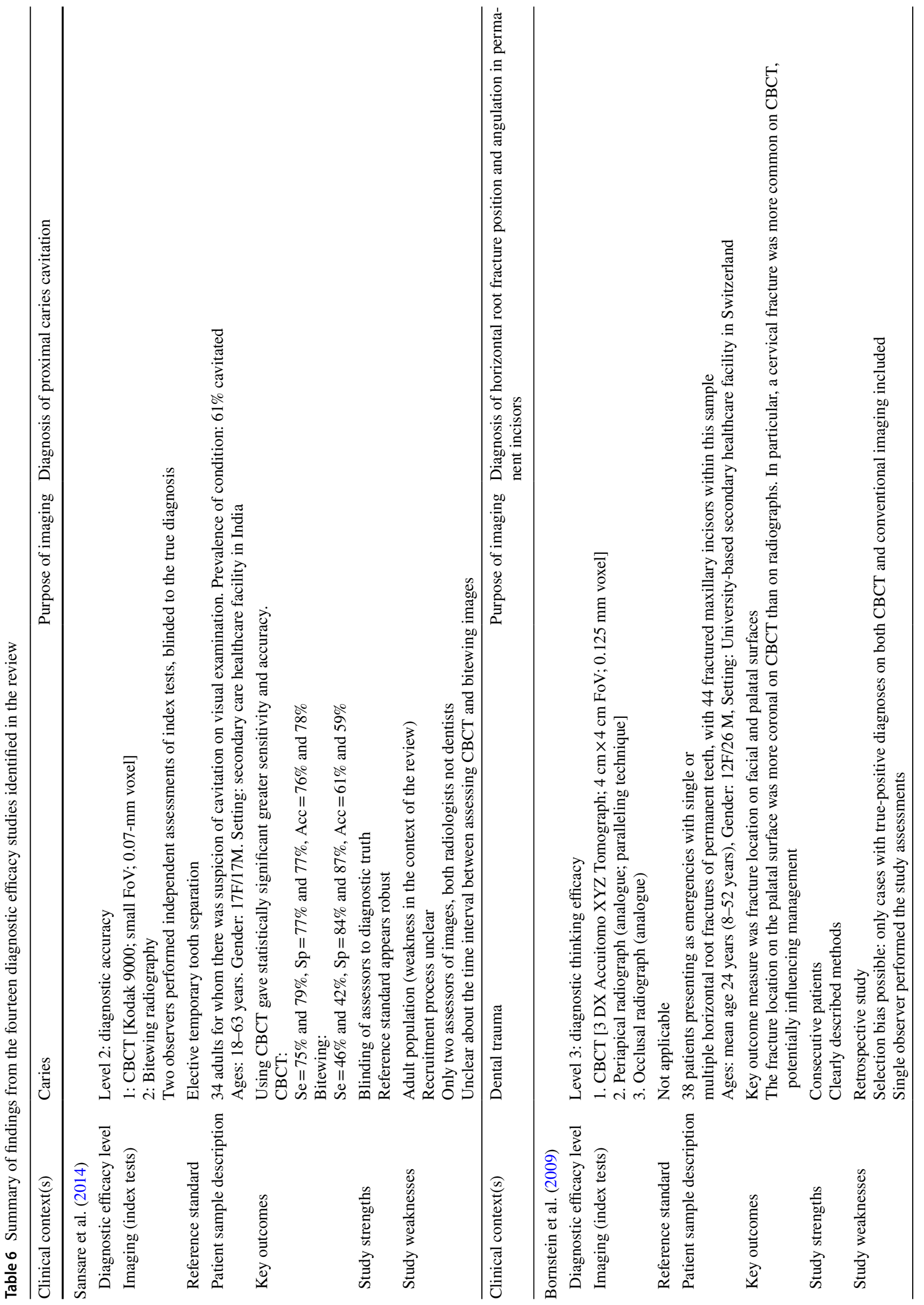




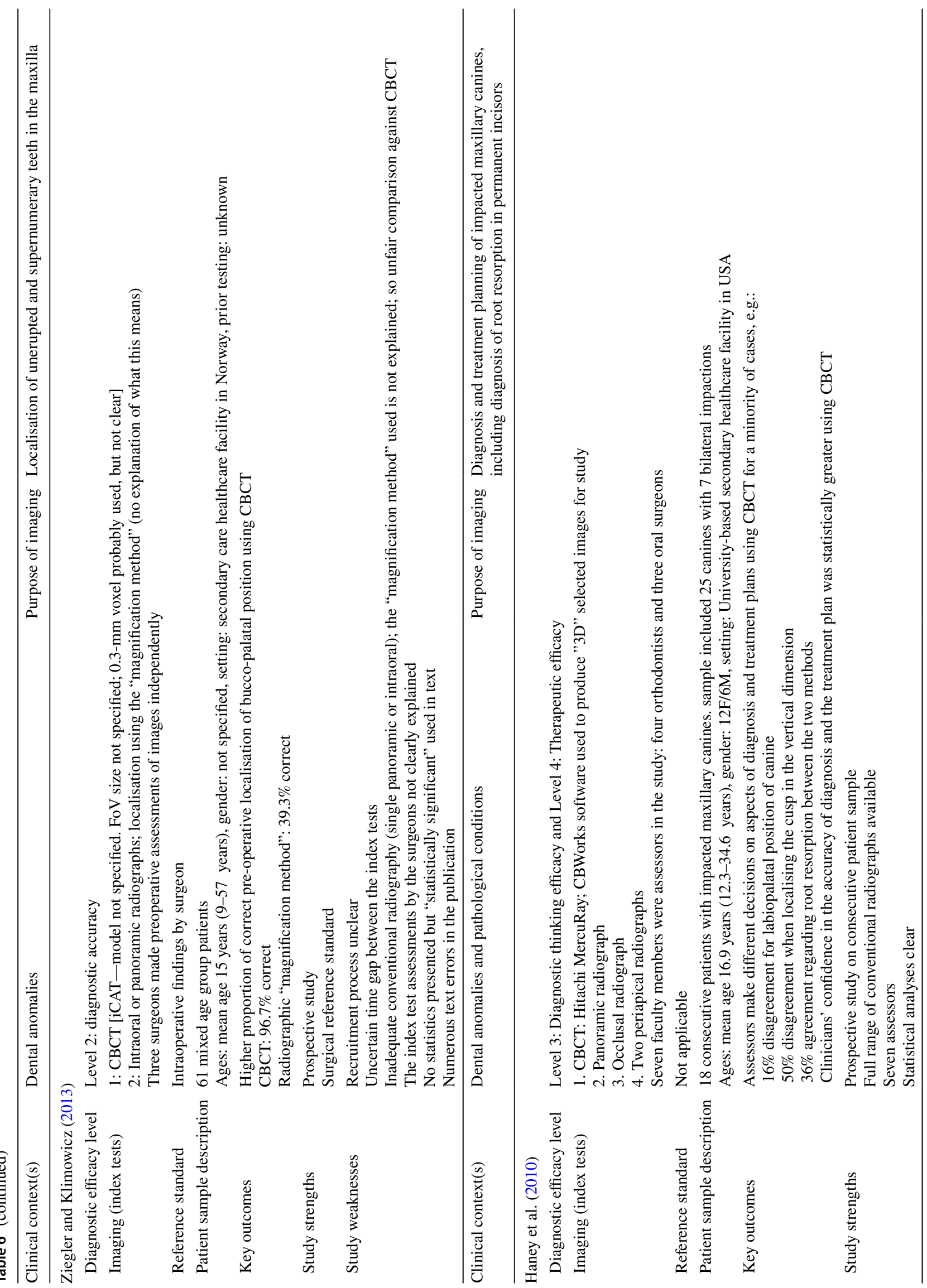




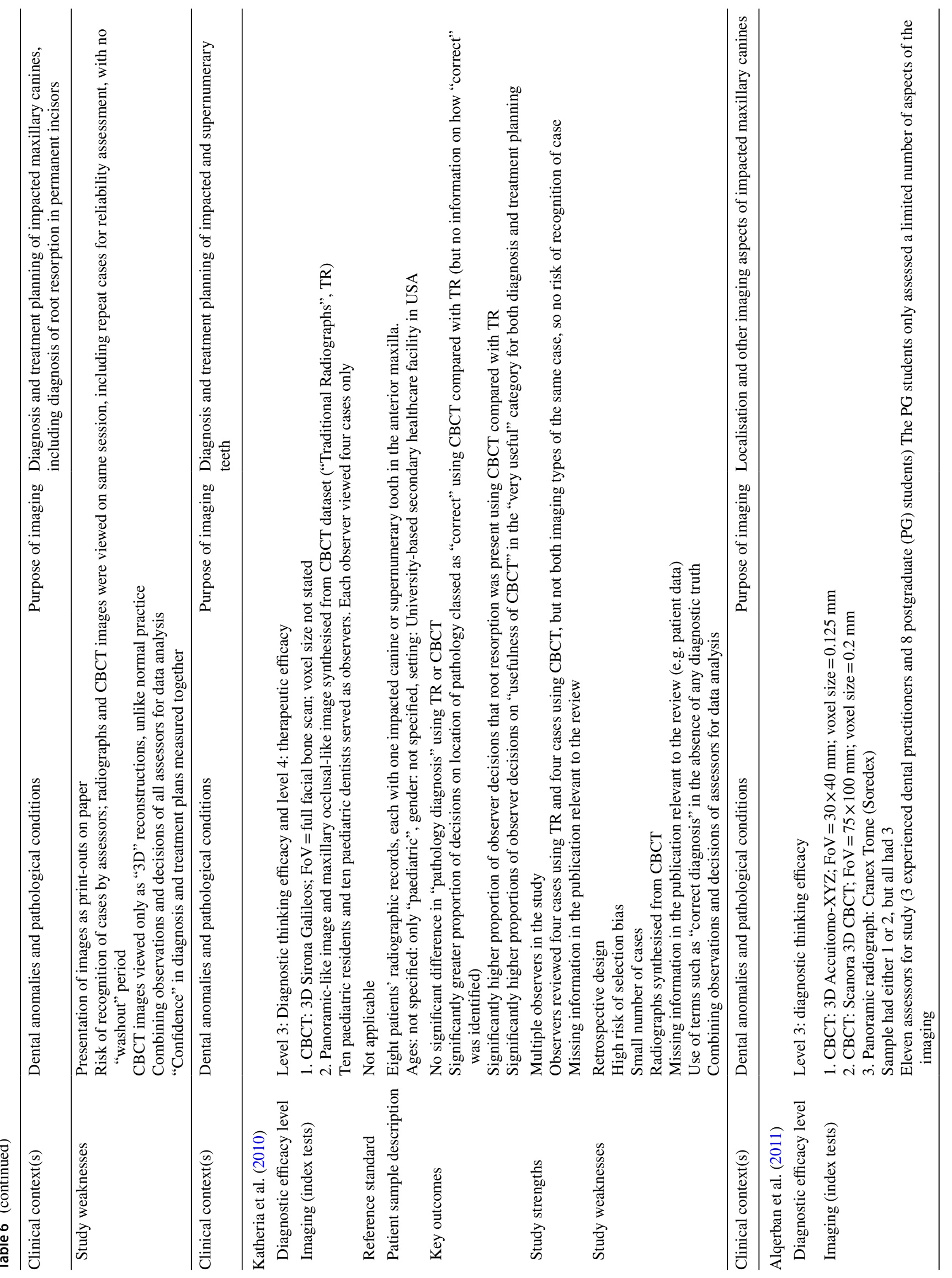




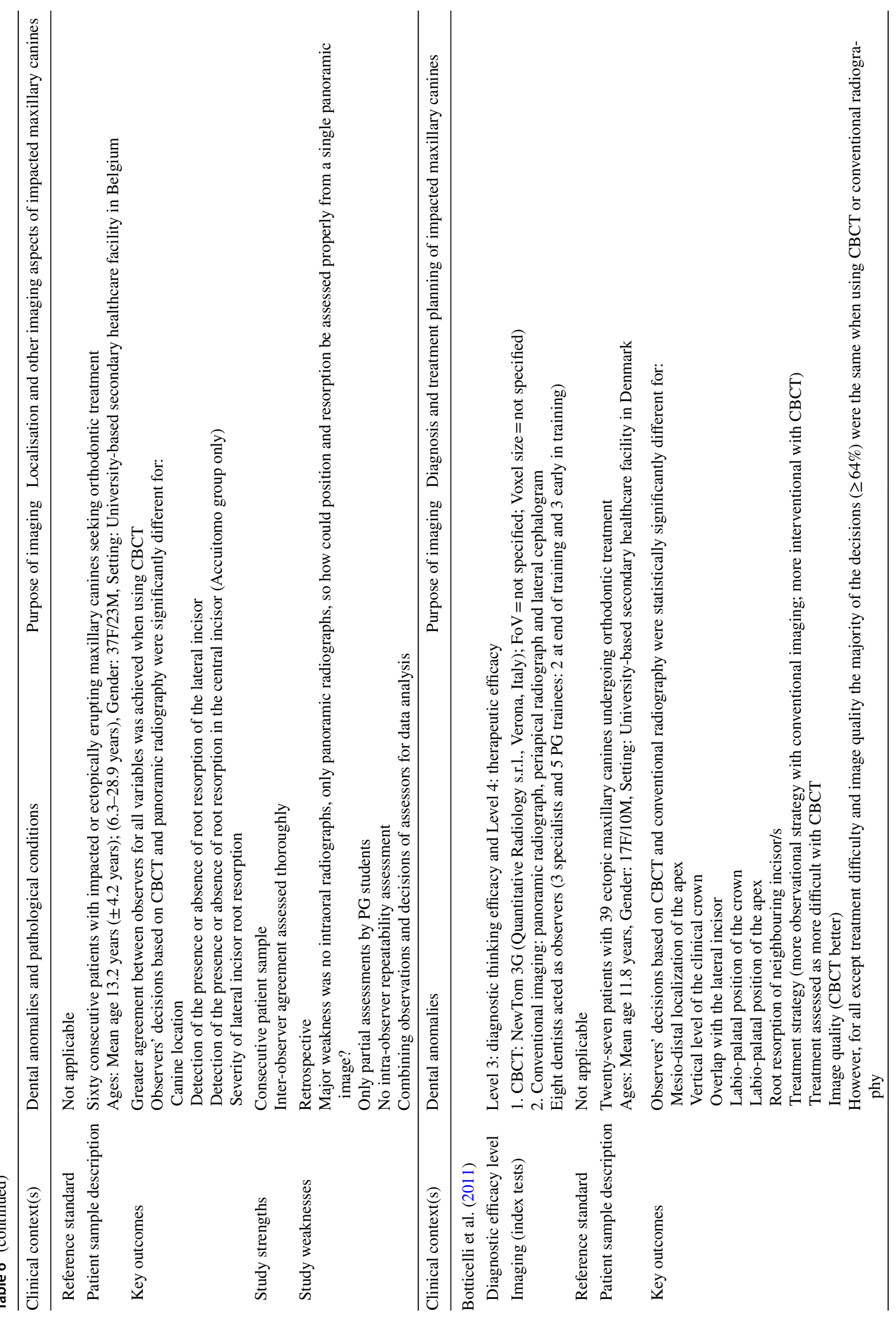




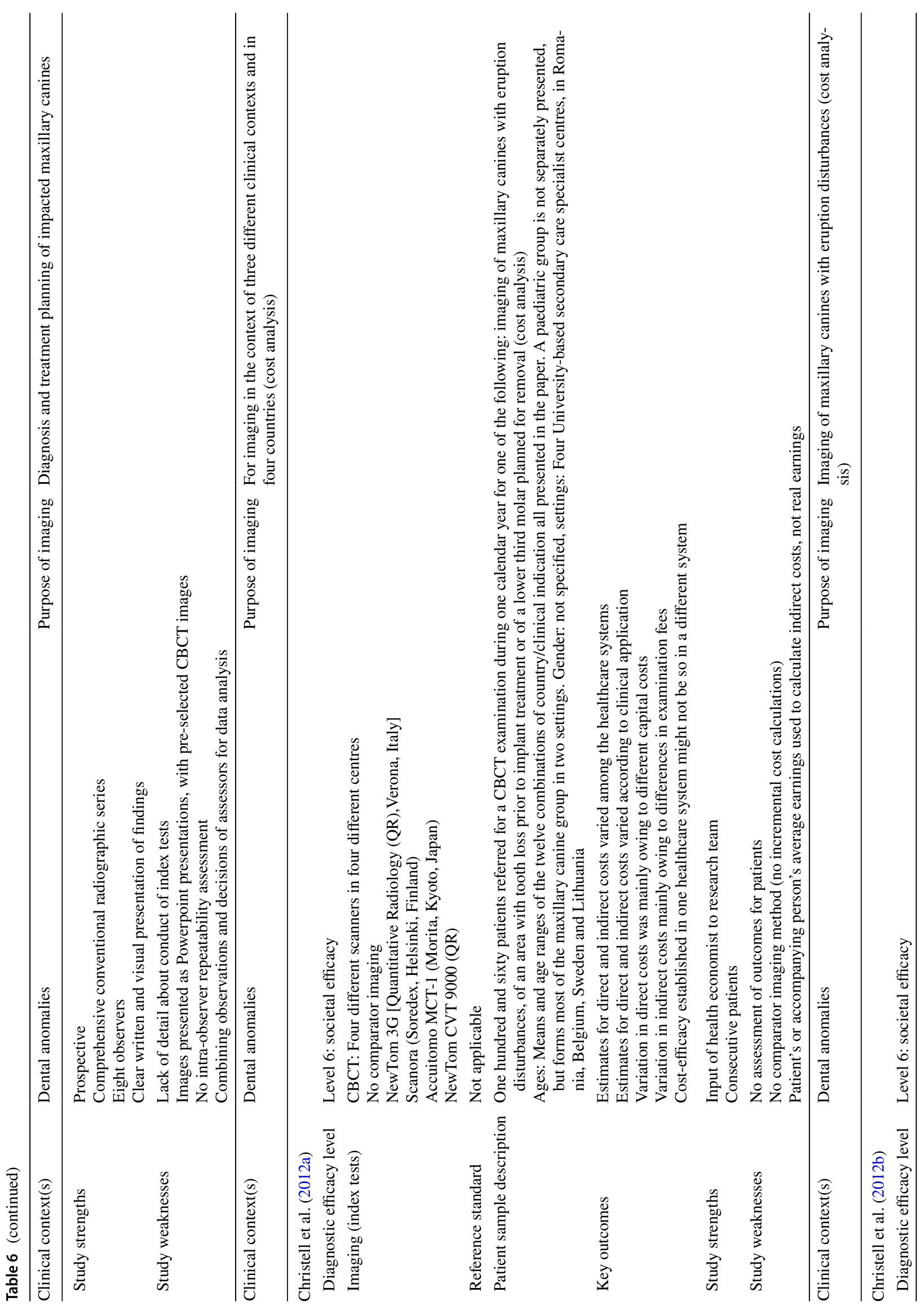




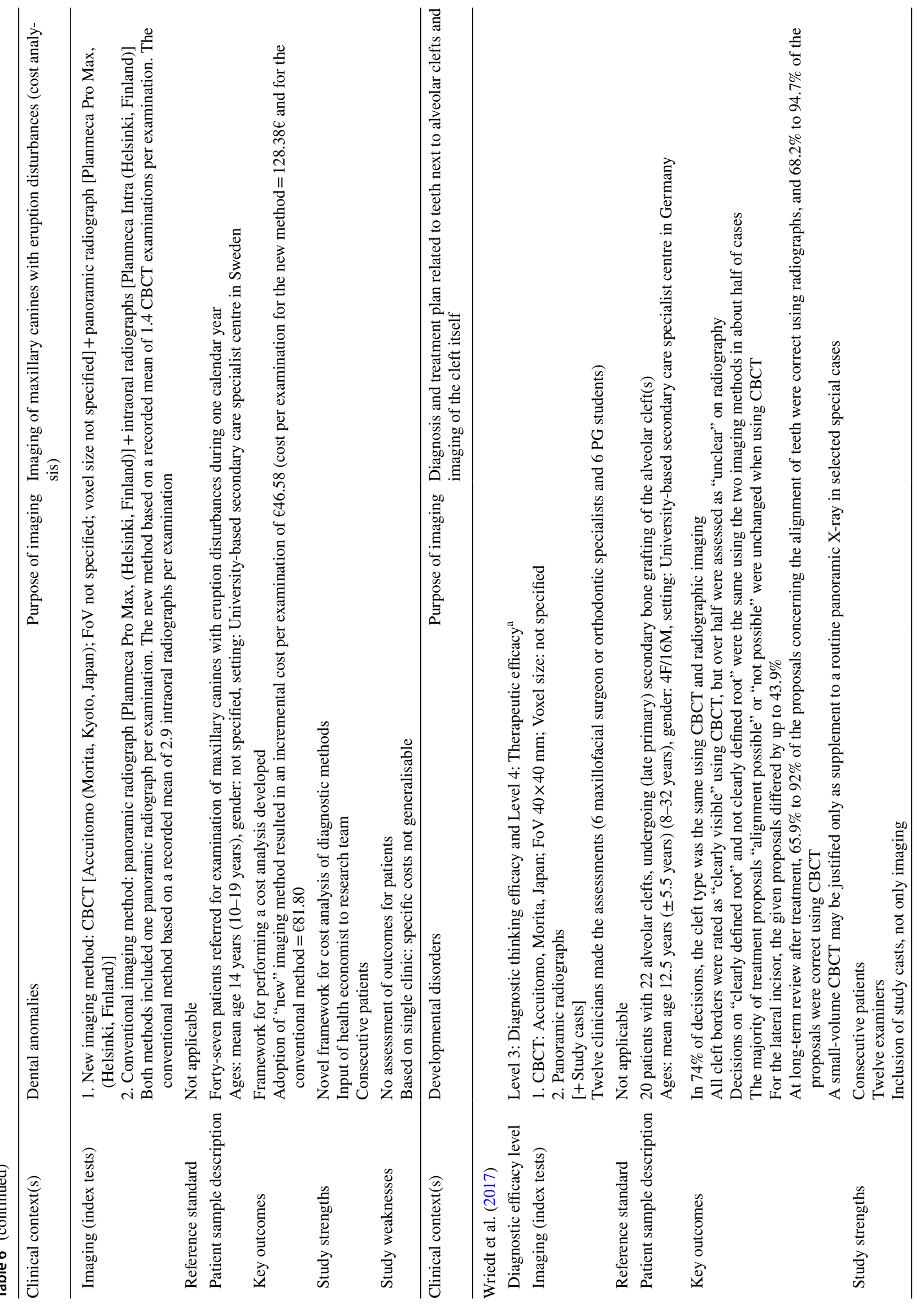




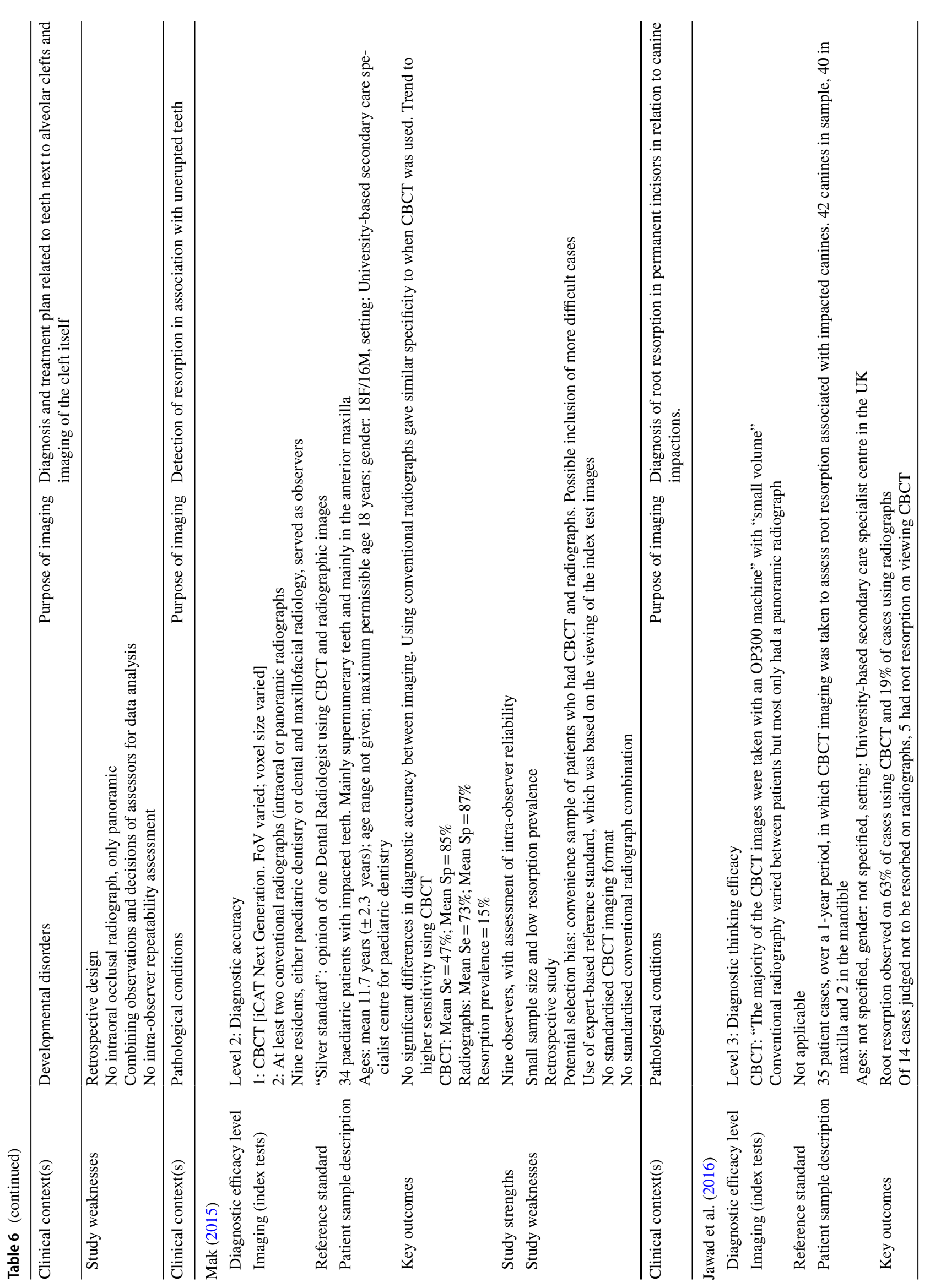




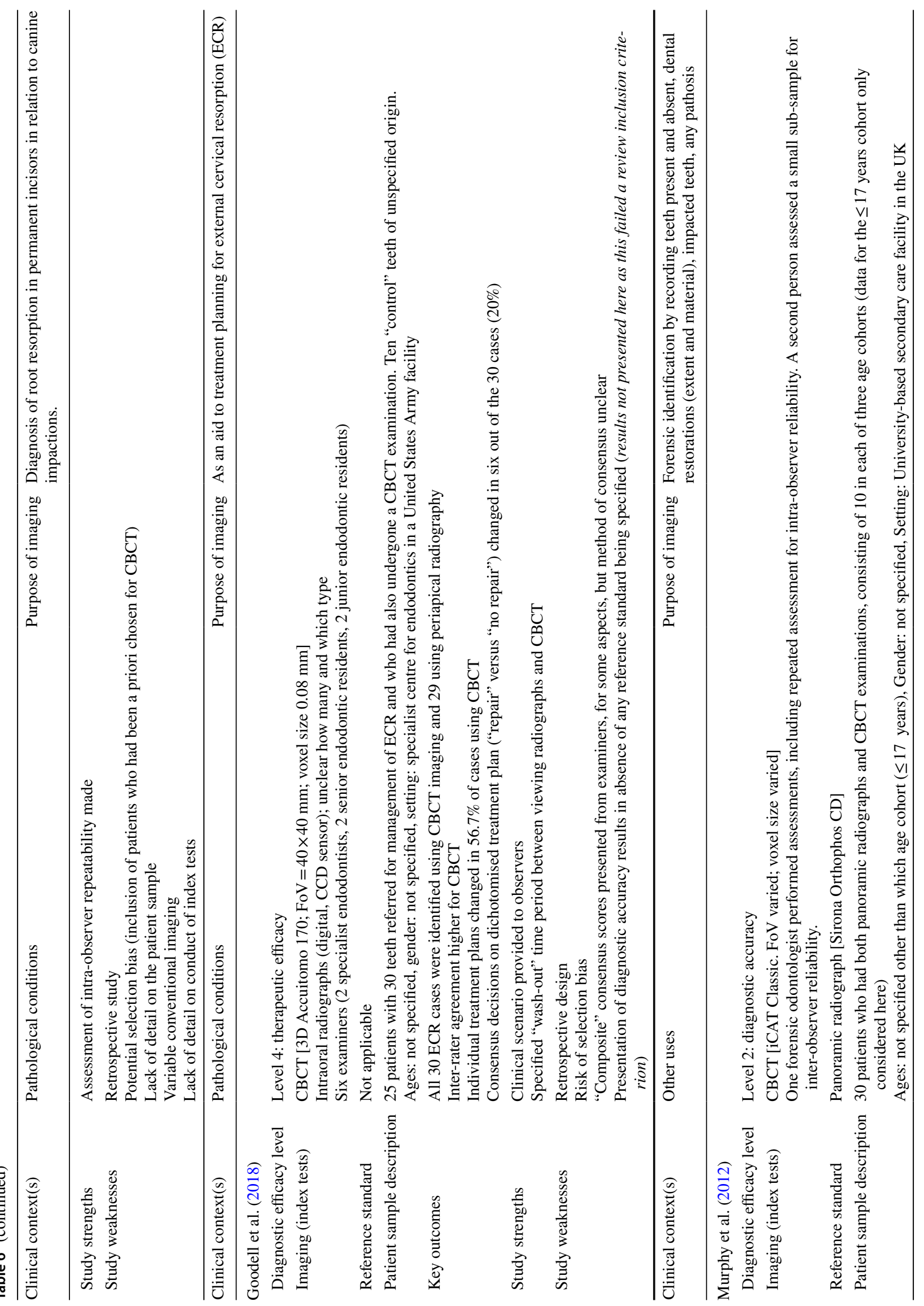




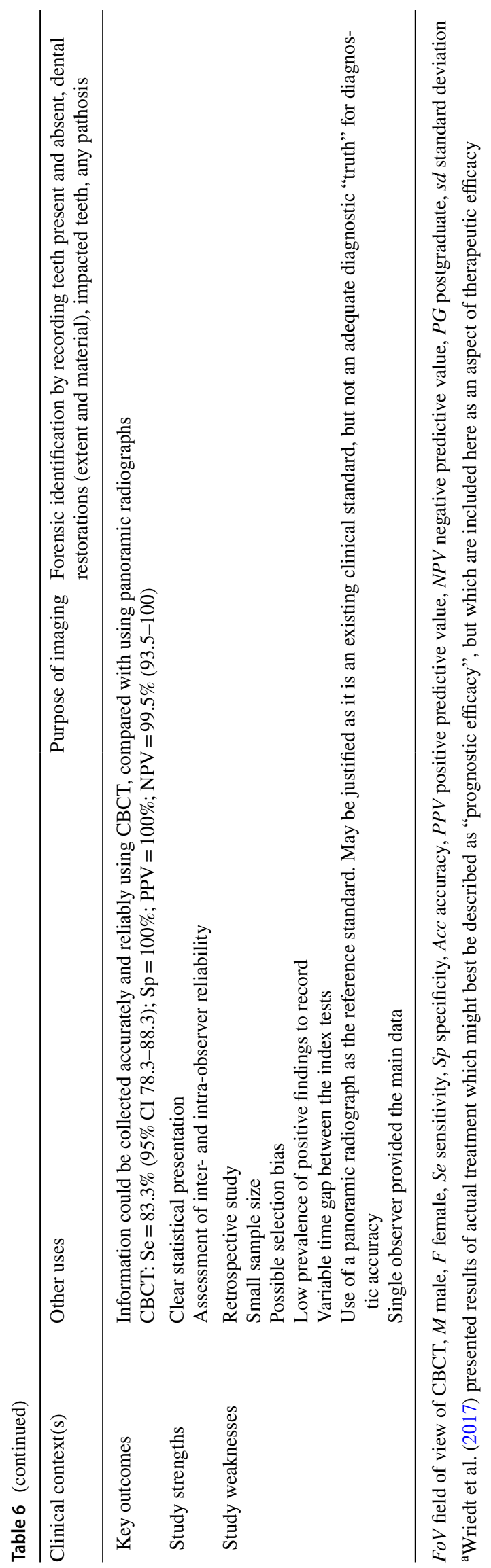

Caries

The evidence relating to $\mathrm{CBCT}$ and caries diagnosis relied predominantly on ex vivo research and most studies showed little difference in diagnostic accuracy when CBCT imaging was used compared with intraoral radiography (Abogazalah and Ando 2017). Ex vivo/in vitro imaging might result in better quality images than those obtained clinically, while artefact from adjacent high attenuation restorations is usually absent. An ex vivo study reported that that cavitation of proximal lesions can be identified more accurately when using CBCT than when using bitewing radiographs (Wenzel et al. 2013). The same group followed this up by a clinical diagnostic accuracy study, included in our review, which confirmed the ex vivo findings and concluded that cavitated caries should be reported on scans taken for other purposes (Sansare et al. 2014). There was no research evidence at the higher levels of diagnostic efficacy. Existing guidelines (Online Resource 1) provided a unanimous view against using CBCT as a standard tool for caries diagnosis.

\section{Acute dental infections}

There was no diagnostic efficacy evidence to suggest that acute dental infection is an indication for CBCT and no relevant guidelines were found. There was evidence, from systematic reviews of ex vivo studies (Online Resources 2 and 6), that using CBCT can give a higher diagnostic accuracy efficacy than conventional radiography for mechanically or chemically prepared periapical bone cavities (Kruse et al. 2015; Leonardi Dutra et al. 2016; Aminoshariae et al. 2018). Evidence from observational studies of patients suggests that using CBCT results in greater numbers of periapical inflammatory lesions being identified than when periapical radiography is used. Although there is a risk that false-positive diagnoses are partly responsible for this, it seems likely that true diagnostic yield from CBCT is higher than from radiographs. Several guideline publications suggest that CBCT might be used as an aid to diagnosis of periapical pathosis when conventional radiography reveals nothing but there are contradictory clinical signs and/or symptoms (Online Resource1).

\section{Dental trauma}

The evidence from systematic reviews of diagnostic accuracy studies predominantly performed ex vivo (Online resources 2 and 6 ) is that, for non-endodontically treated teeth, CBCT can lead to very high diagnostic accuracies for root fracture. Furthermore, these levels of accuracy are higher than when using periapical radiographs (Corbella et al. 2014; Hidalgo Rivas 2014; Long et al. 2014; Chang et al. 2016; Ma et al. 2016; Talwar et al. 2016; Salineiro et al. 
2017). The fact that ex vivo studies lack the impact of patient movement and that the systematic reviews identified risks of bias in a large proportion of these must be recognised. For endodontically treated teeth, most of the evidence suggested that diagnostic accuracy using CBCT for detecting root fracture is lower and that false-positive diagnoses may occur. No solely paediatric studies were available and none on trauma to teeth from the primary dentition. The diagnostic thinking efficacy study by Bornstein et al. (2009), included in our review, found that fracture location on the palatal surface of the root was more coronally placed on CBCT than on radiographs. In particular, a cervical fracture was more commonly seen on CBCT, potentially influencing management. This paper was cited in a review publication by May et al. (2013) who devised a pathway for selection of CBCT that is potentially useful, but which needs further research on its impact.

\section{Dental anomalies}

The evidence in this context dealt with localisation of unerupted and impacted teeth, mainly permanent maxillary canines. Although one diagnostic accuracy study was identified, which reported high accuracy for tooth localisation (Ziegler and Klimowicz 2013), it was of low quality. The diagnostic thinking studies (Haney et al. 2010, Katheria et al. 2010, Alqerban et al. 2011; Botticelli et al. 2011) each reported that using CBCT led to a change in diagnosis of tooth position in a substantial minority of cases, although none of the studies was of the highest quality. Studies which looked at changes in treatment planning using CBCT found these in a proportion of cases, with increased confidence of clinicians. It seems likely that these findings would be true for any unerupted tooth requiring treatment. There was no evidence that patient outcomes are changed, but there was an increase in financial costs when using CBCT (Christell et al. 2012b). There was little diagnostic efficacy evidence for other dental anomalies apart from case studies. These included reports that CBCT was useful to image morphological anomalies of teeth, particularly in the context of planning endodontic treatment, notably for dens invaginatus anomaly, fusion and gemination.

\section{Developmental disorders}

With regard to developmental disorders, the publications identified by the current review were dominated by CBCT imaging of cleft lip and palate (CLP) patients. The evidence suggested that CBCT scanning prior to the procedure of bone grafting is appropriate because it permits a volumetric assessment of the defect (see Online Resource 6). It has advantages over $\mathrm{CT}$ in terms of radiation dose. It might be useful in imaging the teeth around a cleft, but the evidence that this changed treatment plans or prognosis was lacking in the study included in our review (Wriedt et al. 2017). Management of clefts is not a specific role of paediatric dentists, although they may be part of an interdisciplinary team caring for a patient. Apart from CLP patients, the review found a role for CBCT in production of three-dimensional datasets of the facial skeleton. There was very little evidence about the value of CBCT in specific craniofacial syndromes apart from some case studies.

\section{Pathological conditions}

There was a complete lack of paediatric evidence for using $\mathrm{CBCT}$ in periodontal diseases. From the evidence derived from adult clinical studies, CBCT would only be indicated for exceptional cases requiring complex management, for example in regenerative periodontal surgery (Kim and Bassir 2017; Woelber et al. 2018); in the paediatric context, this would be extremely rare.

The evidence regarding the diagnostic value of CBCT for resorption of teeth was weighted towards that associated with unerupted maxillary canine teeth. It is probably the most common paediatric use of CBCT and may be relevant to paediatric dentists working with their orthodontic colleagues. There is a reliance on ex vivo/in vitro studies of diagnostic accuracy. A review of such studies by Yi et al. (2017) found higher sensitivity but equivalent specificity for resorption detection using CBCT compared with intraoral radiography. Artificial lesions, made with a bur or application of acid, are not the same as in vivo resorption. Nonetheless, on balance, it seems reasonable to suggest that a cross-sectional imaging technique, with sufficient image quality, will out-perform a two-dimensional technique for detecting resorptions of teeth, particularly on buccal and lingual surfaces. Studies on diagnostic thinking efficacy reported changes in diagnosis in a proportion of cases when using CBCT (Haney et al. 2010; Katheria et al. 2010; Alqerban et al. 2011; Botticelli et al. 2011; Jawad et al. 2016). Some of the clinical studies cited above did not use intraoral radiographs as comparator imaging, only panoramic radiography, which might under-estimate the value of radiographs compared with CBCT. External cervical resorption is a different entity radiologically to resorption associated with tooth impactions and is impossible to model accurately in ex vivo studies. Goodell et al. (2018), using clinical material, reported that using CBCT changed treatment plans in over half of cases.

The evidence for diagnostic efficacy of CBCT for cysts, benign tumours and other benign conditions was very limited and case-based. 


\section{Other uses}

The application of CBCT for other uses is described in Online Resource 6. One diagnostic accuracy study was included in the review dealing with forensic identification (Murphy et al. 2012), although it was essentially making a comparison of findings with those on panoramic radiographs and has limited relevance to paediatric dental practice. In view of its particular relevance to the paediatric age group, CBCT as part of surgical planning for autotransplantation of teeth is noted, specifically by allowing a three-dimensional model of the tooth to be manufactured and used to prepare the transplant site, along with production of surgical guides (Shahbazian et al. (2013).

\section{Discussion}

The commission for this review was challenging in trying to identify the role of a diagnostic imaging technique in six clinical situations. Each of these six situations, except perhaps "caries", was composed of several or many different contexts, for example, "pathological conditions" and "dental anomalies". Furthermore, the diagnostic efficacy of CBCT in each context could be quite different; for example, while using CBCT might improve diagnostic accuracy for root fracture compared with a radiograph, it might not do so for a luxation injury. Thus, the review was ambitious and would better have been planned as a series of separate systematic reviews.

The decision to include only in vivo studies and those carried out in the paediatric age group, along with exclusion of orthodontic research, fitted the remit given to us. It was a strategy to make the task manageable but inevitably limited the literature. The review found little evidence relating to CBCT specific to the paediatric age group and the inclusion criteria had to be relaxed to allow any diagnostic efficacy studies to be included at all. An important finding was the absence of any research at the patient outcome efficacy level. Because of this, the findings of the supplementary search for systematic reviews based on ex vivo research and those including adult data assumed importance as a source of information.

The purpose of this review was to assist in developing guidelines on indications and contra-indications for using $\mathrm{CBCT}$ in paediatric dentistry. Existing guidelines on the use of CBCT are numerous and it seemed useful to provide guideline statements from these publications (Online Resource 1). The quality of guideline publications was frequently low when appraised using the AGREE II instrument, with many lacking evidence of adequate methodology (Horner et al. 2015). In the current review, no attempt was made to appraise formally those guidelines produced subsequent to that review.

It is important to reiterate some overriding factors when considering a CBCT examination of a paediatric patient. The "Basic Principles" of using CBCT (Horner et al. 2009; European Commission 2012) apply in all situations, particularly that which says "CBCT should only be used when the question for which imaging is required cannot be answered adequately by lower dose conventional (traditional) radiography". Second, a careful assessment is needed to confirm the expectation that the patient can cooperate for the examination, in particular remaining motionless for a prolonged period. Previous experience from other X-ray examinations should assist. If a child has moved in the past when taking a panoramic radiograph, for example, it does not give assurance that CBCT examination will be successful. Movement of patients undergoing $\mathrm{CBCT}$, producing identifiable image artefacts, is more common in paediatric patients (Donaldson et al. 2013; Nardi et al. 2015; Spin-Neto et al. 2015). Indeed, in one study, the risk of movement was 11 times higher in the 15 years or less age group than in the 31 years or older age group (Spin-Neto et al. 2015). Movement affects image quality more if it is repeated, prolonged or multiplanar during the scan acquisition (Spin-Neto et al. 2016). For diagnostic applications requiring fine detail, such as fracture diagnosis, this might be a significant problem and underlines why reliance on ex vivo/in vitro studies is likely to over-estimate diagnostic efficacy of CBCT. A further aspect of this is that high-resolution settings on CBCT equipment which use longer exposure times might increase the chance of movement and a paradoxical loss of image quality when it is most needed (Nardi et al. 2015).

In concluding, a few cautionary points must be made. First, there is ample evidence that the technical efficacy (Table 1) of different CBCT equipment varies. Most of the research evidence is based on studies using "high-end" expensive equipment which usually provides high-quality images. Some CBCT equipment gives inferior image quality and may never have been used in diagnostic research; so, the evidence for diagnostic efficacy for one piece of equipment may not apply to another. Second, the postacquisition adjustment of the images makes a difference to diagnostic value, yet is usually a subjective judgement. Clinicians may or may not adjust the brightness and contrast of scans when evaluating them, but CBCT allows multiple image processing actions to be made which can change the diagnostic value. Third, for a single piece of equipment, achievable image quality is directly related to the X-ray dose and the exposure settings can impact on diagnostic accuracy; exposures should, therefore, be "ALADAIP" (As Low as Diagnostically Acceptable being Indication-oriented and Patient-specific) (Oenning et al. 2018). Fourth, and very importantly, "diagnostic 
accuracy" does not belong to a piece of X-ray equipment, yet too many publications use phrases such as "the diagnostic accuracy of CBCT is...". Diagnostic accuracy (and the two subsequent levels of Fryback and Thornbury's hierarchy) belongs to the person who performs the evaluation of the images. This value varies from individual to individual and within any single individual at different times. Finally, every patient is unique. The process of justification of CBCT examinations should not be reduced to a simple "...is indicated" or "...is contra-indicated" for a particular clinical context; instead, an individual approach is needed when choosing if CBCT is justified or not.

\section{Conclusions}

The review found almost no in vivo study evidence specific to paediatric patients about diagnostic efficacy when using CBCT. A broader review of literature based on systematic reviews of diagnostic efficacy including ex vivo research and not specific to the paediatric age group provided some evidence of relevance.

- CBCT is not indicated for caries diagnosis. Existing scans taken for other reasons that include the teeth should be checked for caries, taking care to be aware of the risk of false-positive diagnoses.

- CBCT might rarely be indicated in exceptional cases of acute infection, where conventional radiography does not reveal the source of that infection but when a dental or bony lesion is suspected.

- CBCT may be indicated for suspected root fracture in teeth without previous endodontic treatment when conventional radiographic examination does not provide adequate information for management.

- Apart from its use in assessing clefts in CLP patients and as an alternative to $\mathrm{CT}$ for producing three-dimensional datasets, there was no evidence of efficacy using CBCT in developmental disorders.

- CBCT is probably indicated for the assessment of resorption (suspected or established) when conventional radiographic examination has proved to be insufficient for management.

- CBCT is probably indicated for imaging of larger bony pathoses (cysts, benign tumours and other benign bony pathosis) to show the lesion characteristics and as an aid in surgical planning.

- Patient cooperation, particularly in the context of movement during long exposure times, is an important aspect to be considered in the justification of CBCT examinations.
Acknowledgments The European Academy of Paediatric Dentistry provided financial support to facilitate this review.

\section{Compliance with ethical standards}

Conflict of interest KH declares that he was a co-author of two publications included in the critical appraisal part of the systematic review of diagnostic efficacy using CBCT. The other authors declare no conflict of interest.

Human and animal rights This article is a systematic review of the literature and no experiments involving humans or animals were performed by any of the authors.

Open Access This article is licensed under a Creative Commons Attribution 4.0 International License, which permits use, sharing, adaptation, distribution and reproduction in any medium or format, as long as you give appropriate credit to the original author(s) and the source, provide a link to the Creative Commons licence, and indicate if changes were made. The images or other third party material in this article are included in the article's Creative Commons licence, unless indicated otherwise in a credit line to the material. If material is not included in the article's Creative Commons licence and your intended use is not permitted by statutory regulation or exceeds the permitted use, you will need to obtain permission directly from the copyright holder. To view a copy of this licence, visit http://creativecommons.org/licenses/by/4.0/.

\section{References}

Abogazalah N, Ando M. Alternative methods to visual and radiographic examinations for approximal caries detection. J Oral Sci. 2017:59:315-22.

Alqerban A, Jacobs R, Fieuws S, Willems G. Comparison of two cone beam computed tomographic systems versus panoramic imaging for localization of impacted maxillary canines and detection of root resorption. Eur J Orthod. 2011;33:93-102.

American Academy of Pediatric Dentistry. Ad Hoc Committee on Pedodontic R, Guideline on prescribing dental radiographs for infants, children, adolescents, and persons with special health care needs. Pediatr Dent. 2012;34:189-91.

Aminoshariae A, Kulild JC, Syed A. Cone-beam computed tomography compared with intraoral radiographic lesions in endodontic outcome studies: a systematic review. J Endod. 2018;44:1626-31.

Aps JK. Cone beam computed tomography in paediatric dentistry: overview of recent literature. Eur Arch Paediatr Dent. 2013;14:131-40.

Bornstein MM, Wolner-Hanssen AB, Sendi P, von Arx T. Comparison of intraoral radiography and limited cone beam computed tomography for the assessment of root-fractured permanent teeth. Dental Traumatol. 2009;25:571-7.

Botticelli S, Verna C, Cattaneo PM, Heidmann J, Melsen B. Two- versus three-dimensional imaging in subjects with unerupted maxillary canines. Eur J Orthod. 2011;33:344-9.

Chang E, Lam E, Shah P, Azarpazhooh A. Cone-beam computed tomography for detecting vertical root fractures in endodontically treated teeth: a systematic review. J Endod. 2016;42:177-85.

Christell H, Birch S, Hedesiu M, Horner K, Ivanauskaite D, Nackaerts $\mathrm{O}$, Rohlin M, Lindh C, SEDENTEXCT consortium. Variation in costs of cone beam CT examinations among healthcare systems. Dentomaxillofac Radiol. 2012a;41:571-7. 
Christell H, Birch S, Horner K, Lindh C, Rohlin M, SEDENTEXCT Consortium. Economic evaluation of diagnostic methods used in dentistry. A systematic review. J Dent. 2014;42:1361-71.

Christell H, Birch S, Horner K, Rohlin M, Lindh C, SEDENTEXCT consortium. A framework for costing diagnostic methods in oral health care: an application comparing a new imaging technology with the conventional approach for maxillary canines with eruption disturbances. Community Dent Oral Epidemiol. 2012b;40:351-61.

Corbella S, Del Fabbro M, Tamse A, Rosen E, Tsesis I, Taschieri S. Cone beam computed tomography for the diagnosis of vertical root fractures: a systematic review of the literature and meta-analysis. Oral Surg Oral Med Oral Pathol Oral Radiol. 2014;118:593-602.

Donaldson K, O'Connor S, Heath N. Dental cone beam CT image quality possibly reduced by patient movement. Dentomaxillofac Radiol. 2013;42:91866873.

Drummond MF, Sculpher MJ, Torrance GW, O'Brien BJ, Stoddart GL. Methods for the economic evaluation of health care programmes. 3rd ed. Oxford: Oxford University Press; 2005.

European Commission. Radiation protection 172, Evidence based guidelines on cone beam CT for dental and maxillofacial radiology. Luxembourg: Office for Official Publications of the European Communities; 2012. https://ec.europa.eu/energy/sites/ener/files/ documents/172.pdf. Accessed 5 Apr 2019.

Evers S, Goossens M, de Vet H, van Tulder M, Ament A. Criteria list for assessment of methodological quality of economic evaluations: consensus on Health Economic Criteria. Int J Technol Assess Health Care. 2005;21:240-5.

Fryback DG, Thornbury JR. The efficacy of diagnostic imaging. Med Decis Making. 1991;11:88-94.

Goodell KB, Mines P, Kersten DD. Impact of cone-beam computed tomography on treatment planning for external cervical resorption and a novel axial slice-based classification system. J Endod. 2018;44:239-44.

Haney E, Gansky SA, Lee JS, Johnson E, Maki K, Miller AJ, Huang JC. Comparative analysis of traditional radiographs and conebeam computed tomography volumetric images in the diagnosis and treatment planning of maxillary impacted canines. Am J Orthod Dentofac Orthop. 2010;137:590-7.

Hidalgo Rivas JA. The diagnostic efficacy of cone beam computed tomography for dental root fractures in non-endodontically treated anterior teeth. A systematic review. In: Aspects of dental cone beam computed tomography in children and young people. $\mathrm{Ph} . \mathrm{D}$. Thesis, University of Manchester; 2014.

Higgins JPT, Green S (eds) Cochrane handbook for systematic reviews of interventions version 5.1.0 [updated March 2011]. The Cochrane Collaboration, 2011. http://www.handbook.cochrane. org. Accessed 4 July 2019.

Horner K, Islam M, Flygare L, Tsiklakis K, Whaites E. Basic principles for use of dental cone beam computed tomography: consensus guidelines of the European Academy of Dental and Maxillofacial Radiology. Dentomaxillofac Radiol. 2009;38:187-95.

Horner K, O'Malley L, Taylor K, Glenny AM. Guidelines for clinical use of CBCT: a review. Dentomaxillofac Radiol. 2015;44:20140225.

Horner K, Shelley AM. Preoperative radiological evaluation of missing single teeth: a review. Eur J Oral Implantol. 2016;9(Suppl 1):S69-88

Jawad Z, Carmichael F, Houghton N, Bates C. A review of cone beam computed tomography for the diagnosis of root resorption associated with impacted canines, introducing an innovative root resorption scale. Oral Surg Oral Med Oral Pathol Oral Radiol. 2016;122:765-71.
Katheria BC, Kau CH, Tate R, Chen JW, English J, Bouquot J. Effectiveness of impacted and supernumerary tooth diagnosis from traditional radiography versus cone beam computed tomography. Pediatr Dent. 2010;32:304-9.

Kim DM, Bassir SH. When is cone-beam computed tomography imaging appropriate for diagnostic inquiry in the management of inflammatory periodontitis? An American Academy of Periodontology Best Evidence Review. J Periodontol. 2017;88:978-98.

Kruse C, Spin-Neto R, Wenzel A, Kirkevang LL. Cone beam computed tomography and periapical lesions: a systematic review analysing studies on diagnostic efficacy by a hierarchical model. Int Endod J. 2015;48:815-28.

Law CS, Douglass JM, Farman AG, White SC, Zeller GG, Lurie AG, Goske MJ. The Image Gently in Dentistry campaign: partnering with parents to promote the responsible use of X-rays in pediatric dentistry. Pediatr Dent. 2014;36:458-9.

Leclercq E, Leeflang MM, van Dalen EC, Kremer LC. Validation of search filters for identifying pediatric studies in PubMed. J Pediatr. 2013;162(629-634):e2.

Leonardi Dutra K, Haas L, Porporatti AL, Flores-Mir C, Nascimento Santos J, Mezzomo LA, Corrêa M, De Luca Canto G. Diagnostic accuracy of cone-beam computed tomography and conventional radiography on apical periodontitis: a systematic review and metaanalysis. J Endod. 2016;42:356-64.

Long H, Zhou Y, Ye N, Liao L, Jian F, Wang Y, Lai W. Diagnostic accuracy of CBCT for tooth fractures: a meta-analysis. J Dent. 2014;42:240-8.

Ludlow JB, Timothy R, Walker C, Hunter R, Benavides E, Samuelson DB, Scheske MJ. Effective dose of dental CBCT-a meta analysis of published data and additional data for nine CBCT units. Dentomaxillofac Radiol. 2015;44:20140197.

Ma RH, Ge ZP, Li G. Detection accuracy of root fractures in conebeam computed tomography images: a systematic review and meta-analysis. Int Endod J. 2016;49:646-54.

Mak K. Root resorption detection by multiple radiographs versus conebeam computed tomography. [Master's thesis]. 2015;1599860:21. https://digital.lib.washington.edu/researchworks/handl e/1773/33709. Accessed 7 Apr 2019.

May JJ, Cohenca N, Peters OA. Contemporary management of horizontal root fractures to the permanent dentition: diagnosis-radiologic assessment to include cone-beam computed tomography. J Endod. 2013;39(3 Suppl):S20-5.

Meads CA, Davenport CF. Quality assessment of diagnostic beforeafter studies: development of methodology in the context of a systematic review. BMC Med Res Methodol. 2009;9:3.

Moher D, Liberati A, Tetzlaff J, Altman DG, The PRISMA Group. Preferred reporting items for systematic reviews and meta-analyses: the PRISMA statement. BMJ. 2009;2009(339):b2535.

Murphy M, Drage N, Carabott R, Adams C. Accuracy and reliability of cone beam computed tomography of the jaws for comparative forensic identification: a preliminary study. J Forensic Sci. 2012;57:964-8.

Nardi C, Borri C, Regini F, Calistri L, Castellani A, Lorini C, Colagrande $\mathrm{S}$. Metal and motion artifacts by cone beam computed tomography (CBCT) in dental and maxillofacial study. Radiol Med. 2015;120:618-26.

Noffke CE, Farman AG, Nel S, Nzima N. Guidelines for the safe use of dental and maxillofacial CBCT: a review with recommendations for South Africa. SADJ. 2011;66(262):4-6.

Oenning C, Jacobs R, Pauwels R, Stratis A, Hedesiu M, Salmon B, DIMITRA Research Group. http://www.dimitra.be. Cone-beam CT in paediatric dentistry: DIMITRA project position statement. Pediatr Radiol 2018;48:308-16.

Salineiro FCS, Kobayashi-Velasco S, Braga MM, Cavalcanti MGP. Radiographic diagnosis of root fractures: a systematic review, 
meta-analyses and sources of heterogeneity. Dentomaxillofac Radiol. 2017;46:20170400.

Sansare K, Singh D, Sontakke S, Karjodkar F, Saxena V, Frydenberg M, Wenzel A. Should cavitation in proximal surfaces be reported in cone beam computed tomography examination? Caries Res. 2014;48:208-13.

Shahbazian M, Jacobs R, Wyatt J, Denys D, Lambrichts I, Vinckier F, Willems G. Validation of the cone beam computed tomographybased stereolithographic surgical guide aiding autotransplantation of teeth: clinical case-control study. Oral Surg Oral Med Oral Pathol Oral Radiol. 2013;115:667-75.

Shea BJ, Reeves BC, Wells G, Thuku M, Hamel C, Moran J, Moher D, Tugwell P, Welch V, Kristjansson E, Henry DA. AMSTAR 2: a critical appraisal tool for systematic reviews that include randomised or non-randomised studies of healthcare interventions, or both. BMJ. 2017;21(358):j4008.

Spin-Neto R, Matzen LH, Schropp L, Gotfredsen E, Wenzel A. Factors affecting patient movement and re-exposure in cone beam computed tomography examination. Oral Surg Oral Med Oral Pathol Oral Radiol. 2015;119:572-8.

Spin-Neto R, Matzen LH, Schropp L, Gotfredsen E, Wenzel A. Movement characteristics in young patients and the impact on CBCT image quality. Dentomaxillofac Radiol. 2016;45:20150426.

Talwar S, Utneja S, Nawal RR, Kaushik A, Srivastava D, Oberoy SS. Role of cone-beam computed tomography in diagnosis of vertical root fractures: a systematic review and meta-analysis. J Endod. 2016;42:12-24.

Theodorakou C, Walker A, Horner K, Pauwels R, Bogaerts R, Jacobs $\mathrm{R}$, SEDENTEXCT Project Consortium. Estimation of paediatric organ and effective doses from dental cone beam CT using anthropomorphic phantoms. Br J Radiol. 2012;85:153-60.

Wenzel A, Hirsch E, Christensen J, Matzen LH, Scaf G, Frydenberg M. Detection of cavitated approximal surfaces using cone beam CT and intraoral receptors. Dentomaxillofac Radiol. 2013;42:39458105.

White SC, Scarfe WC, Schulze RK, Lurie AG, Douglass JM, Farman AG, Law CS, Levin MD, Sauer RA, Valachovic RW, Zeller GG, Goske MJ. The Image Gently in Dentistry campaign: promotion of responsible use of maxillofacial radiology in dentistry for children. Oral Surg Oral Med Oral Pathol Oral Radiol. 2014; 118:257-61.

Whiting PF, Rutjes AWS, Westwood ME, Mallett S, Deeks JJ, Reitsma JB, Leeflang MM, Sterne JAC, Bossuyt PMM. QUADAS-2: a revised tool for the quality assessment of diagnostic accuracy studies. Ann Intern Med. 2011;155:529-36.

Woelber JP, Fleiner J, Rau J, Ratka-Krüger P, Hannig C. Accuracy and usefulness of cbct in periodontology: a systematic review of the literature. Int J Periodontics Restor Dent. 2018;38:289-97.

Wriedt S, Al-Nawas B, Schmidtmann I, Eletr S, Wehrbein H, Moergel M, Jacobs C. Analyzing the teeth next to the alveolar cleft: examination and treatment proposal prior to bone grafting based on three-dimensional versus two-dimensional diagnosis-a diagnostic study. J Craniomaxillofac Surg. 2017;45:1272-7.

Yi J, Sun Y, Li Y, Li C, Li X, Zhao Z. Cone-beam computed tomography versus periapical radiograph for diagnosing external root resorption: a systematic review and meta-analysis. Angle Orthod. 2017;87:328-37.

Ziegler CM, Klimowicz TR. A comparison between various radiological techniques in the localization and analysis of impacted and supernumerary teeth. Indian J Dent Res. 2013;24:336-41.

Publisher's Note Springer Nature remains neutral with regard to jurisdictional claims in published maps and institutional affiliations. 